\title{
Analysis of Nitraria Tangutourum Bobr-Derived Fatty Acids with HPLC-FLD-Coupled Online Mass Spectrometry
}

\author{
Na Hu ${ }^{1,2,3}$, Jian Ouyang ${ }^{2}$, Qi Dong ${ }^{1,3}$ and Honglun Wang ${ }^{1,2,3, *}$ \\ 1 Key Laboratory of Tibetan Medicine Research, Northwest Institute of Plateau Biology, Chinese Academy of \\ Sciences, Xining 810008, China; huna@nwipb.cas.cn (N.H.); qdong@nwipb.cas.cn (Q.D.) \\ 2 Huzhou Plateau Biological Resource Centre of Innovation, Northwest Institute of Plateau Biology, \\ Chinese Academy of Sciences, Huzhou 313000, China; ygzjj@126.com \\ 3 Qinghai Provincial Key Laboratory of Tibetan Medicine Research, Xining 810008, China \\ * Correspondence: hlwang@nwipb.cas.cn; Tel.: +86-09716143857
}

Received: 23 September 2019; Accepted: 22 October 2019; Published: 24 October 2019

check for updates

\begin{abstract}
Fatty acids (FAs) are basic components in plants. The pharmacological significance of FAs has attracted attentions of nutritionists and pharmaceutists. Sensitive and accurate detection of FAs is of great importance. In the present study, a pre-column derivatization and online mass spectrometry-based qualitative and quantitative analysis of FAs was developed. Nineteen main FAs were derivatized by 2-(7-methyl-1H-pyrazolo-[3,4-b]quinoline-1-yl)ethyl-4-methyl benzenesulfonate (NMP) and separated on reversed-phase Hypersil BDS C8 column with gradient elution. All FAs showed excellent linear responses with correlation coefficients more than 0.9996 . The method obtained LOQs between $0.93 \mathrm{ng} / \mathrm{mL}$ and $5.64 \mathrm{ng} / \mathrm{mL}$. FA derivatives were identified by both retention time and protonated molecular ion corresponding to $m / z[\mathrm{M}+\mathrm{H}]^{+}$. A comparative study based on FA contents in peel and pulp, seeds and leaves of Nitraria tangutourum Bobr (NTB) from different geographical origins was performed with the established method. Results indicated that NTB were rich in FAs, and the types and contents of FAs varied among tissues. On the other hand, the same tissue of NTB from different geographical areas differed in the content, but not in type, of FAs.
\end{abstract}

Keywords: fatty acids; Nitraria tangutourum Bobr; HPLC-FLD; online mass spectrometry; different geographical origins

Academic Editor: Daniel Cozzolino

\section{Introduction}

Nitraria Tangutorum Bobr. (NTB), belonging to the Zygophyllacea family, is one of the dominant and endemic species in Qinghai-Tibet Plateau of China [1,2]. NTB plays an important role in resistance to drought, high temperature, salinity and alkalinity and has been used as an ideal material for studying response and adaptability of plants to salinity stress [3]. The fruit of NTB is of high edible value and has been wildly used by locals in making juice, wine and tea. As a traditional herb and food, NTB fruit has been used to treat abnormal menstruation, heart diseases, neurasthenia and dyspepsia in west China $[4,5]$. Modern pharmacological studies showed that NTB fruit possesses multiple pharmacological activities such as hypoglycemia, hypolipidemia, antioxidation, antifatigue, immune regulation and protection against liver damage [5]. Moreover, NTB leaves were used to treat dizziness, headaches, stomach ailments and other digestive diseases [6]. Research showed that alkaloids extracted from NTB leaves exhibit significant anti-tumor activity [7]. Furthermore, NTB leaves were usually used for cattle and sheep feeding for its rich nutrients. The Qinghai-Tibet Plateau is abundant in NTB. Take the Qaidam Basin for example, where there is about $1000 \mathrm{~km}^{2}$ of NTB and the 
available fresh fruits are 1.5-2.5 $\times 10^{5}$ tons per year [8]. As a by-product in processing of NTB, NTB seed accounts for $35 \%-40 \%$ of the total mass and contains high level of fatty acids (FAs) $[5,9]$. Plenty of studies have indicated that FAs are indispensable for the pharmacological activities of medicinal plants $[10,11]$. FAs play a critical role in the prevention and treatment of coronary artery disease [12], cancer [13], diabetes [14], atherosclerosis [15], arthritis [16], hypertension [17] and other inflammatory and autoimmune disorders [18]. Thus, accurate determination of FAs is important for the quality control and safe use of NTB.

Accurate analysis of fatty acids with absorptiometry is challenging, because of its low content in organism and poor light absorption (both UV and visible light) and fluorescence response. The most usually used methods for FA analysis were GC or GC-MS, which have been applied to different research areas [19-23]. However, there existed a lot of shortcomings. For example, high temperatures are not suitable for thermally unstable FA derivatives, which usually make the data unsatisfactory [24]. In addition, explosiveness, toxicity and carcinogenicity of derivative reagents limit the usage of GC or GC-MS in FA analysis $[25,26]$. It has been proposed that the injection technique, especially vaporizing injectors, is one of the main sources of error in quantitative GC. Moreover, in ESI $450{ }^{\circ} \mathrm{C}$ often are required in order to active desolvation processes [26]. Compared with the GC method, HPLC-coupled with derivatization can overcome these disadvantages. For example, HPLC allows FA to be converted to a large number of different derivatives, and avoided the formation of less polar compounds as well as tailing peaks that significantly increased detection sensitivity [27]. Moreover, the availability of various strong UV-absorbing or fluorescent molecules, column packing materials and solvents can increase the selectivity and sensitivity of analysis by HPLC [28]. More importantly, low temperature during HPLC analysis can reduce the risk of isomerization of double bonds and the separated components can easily be collected and recovered from the mobile phase for further analysis with complementary techniques, such as mass spectrometry and nuclear magnetic resonance of infrared spectroscopy [29]. Therefore, pre-column derivatization combined with different fluorescence-labeling reagents has become the prevailing technique in FA analysis [30-34].

In the present study, a novel fluorescent reagent 2-(7-methyl-1H-pyrazolo-[3,4-b]quinoline-1-yl) ethyl-4-methyl benzenesulfonate (NMP) was used as the pre-column labeling reagent and was applied to the analysis of FAs in NTB. Considering the wide distribution of NTB in Qaidam Basin, we collected NTB samples from seven different geographical regions for the detection. To fully utilize the NTB resource, in addition to the previously studied NTB seeds, we also examined the FAs in peel, pulp and leaves of NTB. Generally, the aims of the present work were: (1) to develop a selective and sensitive method for the determination of FAs in Nitraria tangutourum Bobr of different origins by using NMP pre-column labeling and fluorescence detection which was coupled with online APCI-MS; (2) to compare the FA composition and content in NTB of different origins. Our study might provide a method for safety assessment and quality control in development of NTB-related products.

\section{Results and Discussion}

\subsection{Optimization of Derivatization Conditions}

\subsubsection{Effect of Co-Solvents on Derivatization}

The presence of co-solvents directly affects efficiency of the derivatization reaction. In this study, DMF, acetonitrile, DMSO and THF were used as co-solvents, and their effects on the derivatization efficiency were investigated. The results showed that, with DMF as a co-solvent, the FA derivatives generated strong fluorescence and the derivatization efficiency was 1.5 to 2 times of that derived from other solvents-involved reactions. Meanwhile, due to the high solubility of lipids in DMF, the precipitation of hydrophobic long-chain FAs can be significantly reduced. Therefore, DMF was used as co-solvent in the following studies. 


\subsubsection{Effect of Basic Catalysts on Derivatization}

With DMF as co-solvent, the effects of different basic reagents on the catalytic effect of derivatization, including sodium carbonate, potassium oxalate, potassium carbonate and sodium acetate, were studied. Results showed that, compared with other catalysts, $\mathrm{K}_{2} \mathrm{CO}_{3}$ made the fluorescence intensity of the derivative product 1-2 times higher. Therefore, $\mathrm{K}_{2} \mathrm{CO}_{3}$ was used as the catalyst for the derivatization reaction. The highest derivatization reaction efficiency was obtained when the amount of $\mathrm{K}_{2} \mathrm{CO}_{3}$ was between $25 \mathrm{mg}$ and $30 \mathrm{mg}$, and $25 \mathrm{mg}$ was selected in following studies.

\subsubsection{Effect of NMP Concentration on Derivatization}

With $\mathrm{K}_{2} \mathrm{CO}_{3}$ as a catalyst and DMF as a co-solvent, the influence of the amount of derivatizing reagent on the derivatization efficiency was investigated. Results showed that the derivatization reaction was insufficient when the amount of derivatization reagent was less than three times of that of the FAs. Along with the increase in amount of derivatization reagent, the fluorescence intensity increased. Fluorescence intensity reached the highest value when the amount of derivatizing reagent is five times of that of FAs, and no further increase of fluorescence intensity was observed when a higher amount of derivatizing reagents was added.

\subsubsection{Effect of Temperature and Time on Derivatization}

Temperature was also an important factor affecting the efficiency of derivatization. When the temperature was lower than $80^{\circ} \mathrm{C}$, derivatization reaction was usually incomplete even after a long time. In contrast, when the temperature was set at $90^{\circ} \mathrm{C}$, the derivatization efficiency reached the highest. Interestingly, when the temperature increased further to $100^{\circ} \mathrm{C}$, the derivatization efficiency decreased. This may be due to the degradation of the derivatized product at high temperature. Ranging from 10 to $60 \mathrm{~min}$ at an interval of $10 \mathrm{~min}$, the effect of reaction time on the derivatization efficiency was investigated. Results showed that the derivatization efficiency reached maximal value at $30 \mathrm{~min}$.

In summary, our studies suggest the optimal derivatization conditions as follows: DMF as co-solvent, $25 \mathrm{mg}$ of $\mathrm{K}_{2} \mathrm{CO}_{3}$ as catalyst, ratio between derivatizing reagent and FAs at 5:1, reaction temperature at $90{ }^{\circ} \mathrm{C}$ and reaction time for $30 \mathrm{~min}$ (Figure 1). Under these conditions, full reaction can be guaranteed.
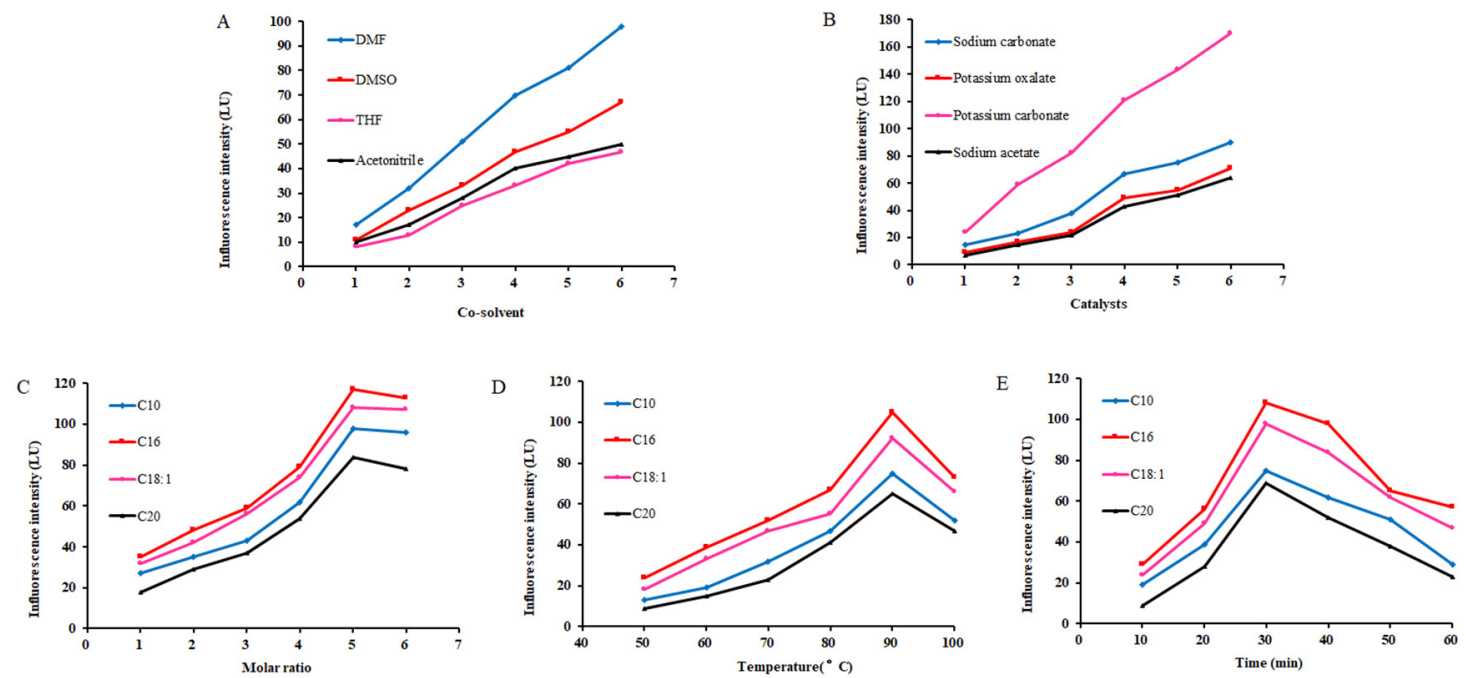

Figure 1. Optimization of derivatization conditions ((A): Co-solvent; (B): catalysts; (C): molar ratio; (D): temperature; (E): time). 


\subsection{Chromatographic Separation and Mass Spectrometry Identification}

\subsubsection{HPLC Separation}

In order to optimize the chromatographic separation conditions, the influence of the chromatographic column and mobile phase were investigated. Compared to C8 columns, C18 columns showed better separation effect for FAs. However, the separation time exceeded $100 \mathrm{~min}$ for C18 column-based separation. Therefore, $\mathrm{C} 8$ column was chosen for following experiments. Several columns such as Hypersil BDS C8 $(200 \mathrm{~mm} \times 4.6 \mathrm{~mm}, 5 \mu \mathrm{m})$, Zorbax Eclipse XDB-C8 $(200 \mathrm{~mm} \times 4.6 \mathrm{~mm}$, $5 \mu \mathrm{m})$ and Hypersil GOLD C8 $(200 \mathrm{~mm} \times 4.6 \mathrm{~mm}, 5 \mu \mathrm{m})$ were tested and the separation efficiency was compared. Results showed that Hypersil BDS C8 column achieved complete separation of all 19 FAs within $52 \mathrm{~min}$. For the mobile phase, usage of acetonitrile achieved faster separation and better resolution than methanol.

\subsubsection{MS Identification}

The positive ion mode of the atmospheric pressure chemical ionization (APCI) was used to further identify the derivatives of FAs. The molecular ion peaks and fragment ion peaks produced by FA derivatives were listed in Table 1. Figure 2 showed the mass spectrum of oleic acid derivatization. $\mathrm{m} / \mathrm{z} 492.5$ was the molecular ion peak with high specific intensity. $\mathrm{m} / \mathrm{z} 228.2,210.2$ and 183.8 are the fragment ion peaks generated after the molecular ion collision. The fragment ion peak $\mathrm{m} / \mathrm{z} 228.2 \mathrm{was}$ derived from cleavage of the O-CO bond of FA derivatives, while fragment ion peak 210.2 is from cleavage of the $\mathrm{C}-\mathrm{OCO}$ bond from the FA derivatives. The fragment 183.8 was derived from the cleavage of N-C bond from the internal structure of the N-side chain. Fragment ion peaks $m / z 210.2$ and $m / z 228.2$ were valid indicator for existence of FA derivatives.
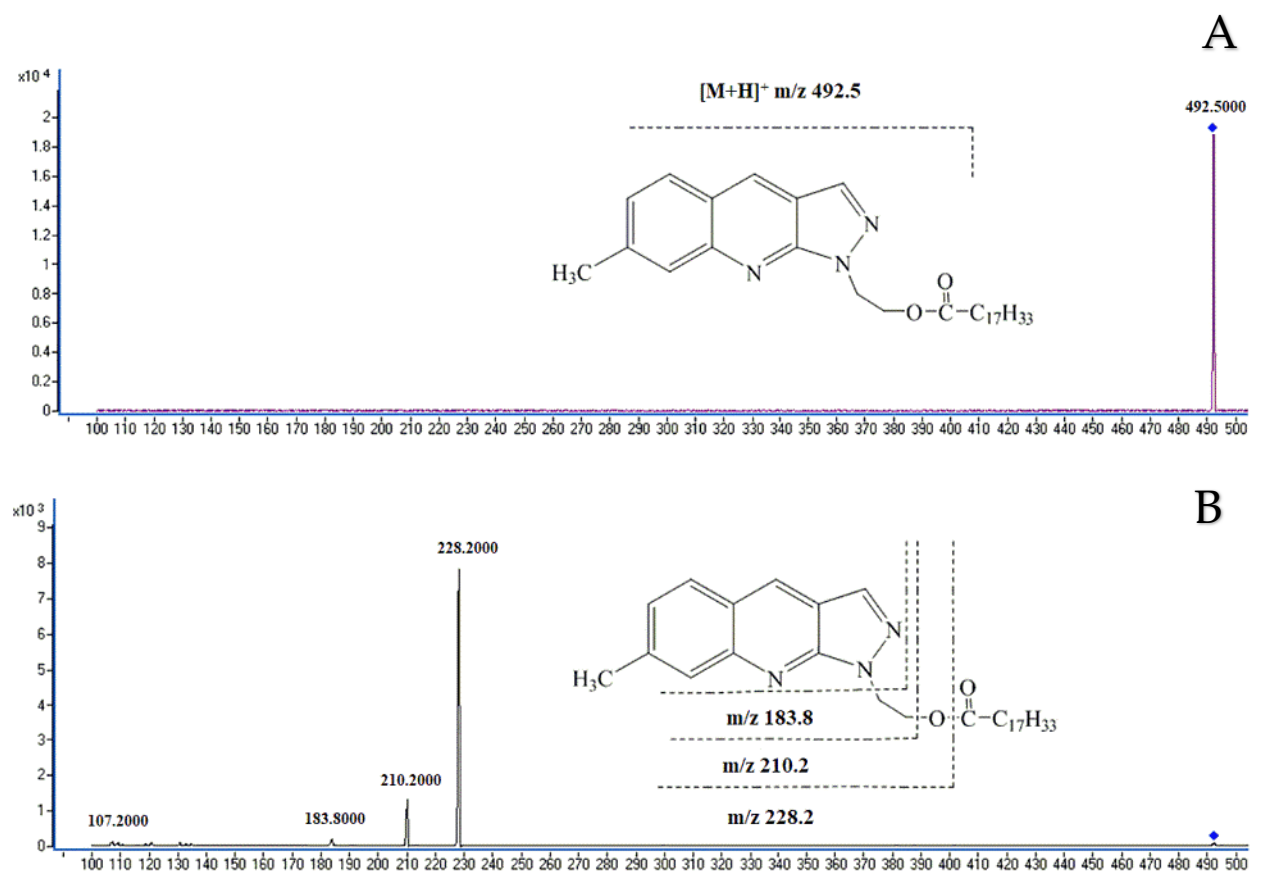

Figure 2. MS spectra of the representative oleic acid derivative and fragmentation pattern of the protonated molecular ion. (A) molecular ion peak of the oleic acid derivative. (B) fragmentation pattern of protonated molecular ion 
Table 1. MS data, linearity, correlation coefficient, limits of detection (LODs), limits of quantification (LOQs), precision and recovery for the quantification method of fatty acids.

\begin{tabular}{|c|c|c|c|c|c|c|c|}
\hline Fatty Acid & $\begin{array}{c}\text { MS } \\
{[\mathbf{M}+\mathbf{H}]^{+}}\end{array}$ & Linearity & $\begin{array}{l}\text { Correlation } \\
\text { Coefficient }\end{array}$ & $\begin{array}{c}\text { LOD } \\
(\mathrm{ng} / \mathrm{mL})\end{array}$ & $\begin{array}{c}\text { LOQ } \\
(\mathrm{ng} / \mathrm{mL})\end{array}$ & $\begin{array}{c}\text { Recovery } \\
(\%)\end{array}$ & $\begin{array}{c}\text { RSD } \\
(\%)\end{array}$ \\
\hline C6 & 326.5 & $y=5.86 x+8.21$ & 0.9996 & 0.42 & 0.93 & 99.8 & 1.44 \\
\hline $\mathrm{C} 7$ & 340.5 & $y=9.25 x-12.43$ & 0.9998 & 0.54 & 1.24 & 96.5 & 2.56 \\
\hline $\mathrm{C} 8$ & 354.5 & $y=6.21 x+1.45$ & 0.9996 & 0.49 & 1.45 & 99.1 & 2.68 \\
\hline C9 & 368.5 & $y=6.44 x-5.26$ & 0.9997 & 0.57 & 1.57 & 97.5 & 3.14 \\
\hline $\mathrm{C} 10$ & 382.5 & $y=4.86 x-8.24$ & 0.9999 & 0.49 & 1.24 & 102.6 & 2.25 \\
\hline $\mathrm{C} 11$ & 396.5 & $y=3.24 x+2.49$ & 0.9996 & 0.62 & 1.65 & 98.3 & 0.98 \\
\hline $\mathrm{C} 12$ & 410.5 & $y=6.72 x+0.24$ & 0.9998 & 0.69 & 1.98 & 92.4 & 2.67 \\
\hline $\mathrm{C} 13$ & 424.5 & $y=4.38 x+2.21$ & 0.9997 & 0.78 & 2.14 & 99.5 & 3.21 \\
\hline C18:3 & 488.5 & $y=7.25 x+4.46$ & 1 & 0.86 & 2.35 & 98.9 & 3.65 \\
\hline $\mathrm{C} 14$ & 438.5 & $y=6.24 x+7.98$ & 0.9999 & 1.04 & 2.97 & 94.5 & 1.98 \\
\hline C16:1 & 464.5 & $y=6.74 x-2.38$ & 0.9998 & 1.15 & 3.01 & 91.8 & 2.56 \\
\hline C18:2 & 490.5 & $y=8.99 x-5.66$ & 0.9999 & 1.31 & 3.25 & 103.2 & 2.87 \\
\hline $\mathrm{C} 16$ & 466.5 & $y=9.27 x-10.29$ & 0.9996 & 1.42 & 3.96 & 97.6 & 1.99 \\
\hline C18:1 & 492.5 & $y=8.02 x+6.08$ & 0.9997 & 1.63 & 4.42 & 98.3 & 3.25 \\
\hline $\mathrm{C} 17$ & 480.5 & $y=12.54+0.72$ & 0.9997 & 1.71 & 4.54 & 95.5 & 2.76 \\
\hline C18 & 494.5 & $y=4.36 x+2.58$ & 0.9999 & 1.59 & 4.36 & 99.6 & 3.24 \\
\hline C20:1 & 520.5 & $y=10.22 x-8.75$ & 0.9996 & 1.87 & 5.23 & 92.7 & 2.96 \\
\hline C19 & 508.5 & $y=12.45 x+14.57$ & 0.9996 & 1.79 & 5.49 & 98.4 & 3.75 \\
\hline $\mathrm{C} 20$ & 522.5 & $y=3.89 x-1.24$ & 0.9998 & 2.03 & 5.64 & 99.5 & 3.29 \\
\hline
\end{tabular}

\subsection{Method Validation}

The established method was validated by linearity, limits of detection (LODs), limits of quantification (LOQs), precision and accuracy (Table 1). Linearity data was generated by plotting the peak areas versus corresponding concentrations of the 19 FA standards. The correlation coefficients were found to be $>0.996$, which indicated excellent linearity of the analyses. LODs and LOQs are the concentration at which signal-to-noise ratio $(\mathrm{S} / \mathrm{N})$ is 3 and 10 , respectively. The results showed that LODs and LOQs fell in the range of $0.43-2.03 \mathrm{ng} / \mathrm{mL}$ and $0.93-5.64 \mathrm{ng} / \mathrm{mL}$, correspondingly. The precision was determined by parallel analysis of the actual sample three times. Results showed that precision of the method (expressed by relative standard deviation) is between $0.98 \%$ and $3.75 \%$. To determine the accuracy, a recovery experiment was conducted and recovery rates between $91.8 \%$ and $103.2 \%$ for all FAs were obtained.

\subsection{Analysis and Evaluation of FAs in NTB from Different Geographical Origins}

The content of FAs in different tissues of NTB with different geographical origins was analyzed by the established method. The excess of the derivatizing reagent NMP could ensure full derivatization of all FAs in the samples. In addition, in order to ensure the accuracy of results, standard solution was measured after every five samples to compensate for the possible deviation in retention time. A representative chromatogram of FA standard solution and FAs in peel and pulp, seeds and leaves of NTB were shown in Figure 3. The detailed data of FA content in NTB was listed in Tables 2-4.

Combined with Figure 3 and Tables 2-4, it can be seen that all tested tissues of NTB contain a large amount of unsaturated FAs, which accounted for more than $60 \%$ of total FAs. The content of unsaturated FAs in leaves was the highest, followed by seeds, peel and pulp. The main unsaturated FA varied among tissues. Analysis of FAs in NTB from different origins showed that unsaturated FA in the peel and pulp was mainly C18:1, with a content of $116.33-183.04 \mu \mathrm{g} / \mathrm{g}$, followed by C18:3 $(89.21-145.23 \mu \mathrm{g} / \mathrm{g})$ and C18: $2(72.43-125.16 \mu \mathrm{g} / \mathrm{g})$. In addition, there existed a small amount of C20:1 $(9.54-13.21 \mu \mathrm{g} / \mathrm{g})$ and C16:1 (2.28-13.98 $\mu \mathrm{g} / \mathrm{g})$. In the Dulan area, the highest content of unsaturated FA was C18:2 (177.61 $\mu \mathrm{g} / \mathrm{g})$, followed by C18:1 (135.45 $\mu \mathrm{g} / \mathrm{g}), \mathrm{C} 18: 3(112.11 \mu \mathrm{g} / \mathrm{g})$ and C20:1 $(12.31 \mu \mathrm{g} / \mathrm{g})$, with $\mathrm{C} 16: 1$ as the lowest content $(3.06 \mu \mathrm{g} / \mathrm{g})$. In the seed of NTB, the highest content of unsaturated FA 
was C18:2 (154.12-487.22 $\mu \mathrm{g} / \mathrm{g})$, followed by C18:1 (123.89-208.23 $\mu \mathrm{g} / \mathrm{g})$ and C18:3 (24.43-57.92 $\mu \mathrm{g} / \mathrm{g})$, with $\mathrm{C} 16: 1$ as the lowest content $(3.22-6.13 \mu \mathrm{g} / \mathrm{g})$. The unsaturated FA in leaves of NTB was mainly C18:3 (566.24-1297.51 $\mu \mathrm{g} / \mathrm{g})$, followed by C18:2 (184.32-595.44 $\mu \mathrm{g} / \mathrm{g}), \mathrm{C} 18: 1(39.56-163.29 \mu \mathrm{g} / \mathrm{g})$ and C16:1 (9.29-21.21 $\mu \mathrm{g} / \mathrm{g})$. C20:1 was not detected in seeds or leaves of NTB. In terms of the saturated FAs, C16 and C18 were found to be the major constituents in different tissues of NTB. Their content in leaves was the highest, which was followed by seeds, and peel and pulp contained the lowest. The content of C16 in peel and pulp, seeds and leaves were $45.04-59.38 \mu \mathrm{g} / \mathrm{g}, 58.63-80.92 \mu \mathrm{g} / \mathrm{g}$ and $187.38-427.82$ $\mu \mathrm{g} / \mathrm{g}$, respectively, while that of C18 were $23.01-56.51 \mu \mathrm{g} / \mathrm{g}, 31.67-88.90 \mu \mathrm{g} / \mathrm{g}$ and $48.24-89.05 \mu \mathrm{g} / \mathrm{g}$, respectively. In addition to $\mathrm{C} 16$ and C18, a certain amount of C14, C20 and a small amount of C6, C9 and C12 was found in peel, pulp and seeds. Furthermore, a certain amount of C14 C20 and a small amount of C6, C12 was observed in leaves. In summary, there is basically no difference in the types of FAs in the same tissue of NTB from different areas, while the content could vary Peak labels: C6, hexanoic acid; C7, heptanoic acid; C8, caprylic acid; C9, pelargonic acid; C10, decoic acid; C11, undecanoic acid; C12, dodecanoic acid; C13, tridecanoic acid; C18:3, 8,11,14-octadecatrienoic acid; C14, myristic acid; C16:1, 9-hexadecenoic acid; C18:2, 9,12-octadecadienoic acid; C16, hexadecanoic acid; C18:1, 12-octadecenoic acid; C17, heptadecanoic acid; C18, octadecanoic acid; C20:1, 11-eicosenoic acid; C19, nonadecanoic acid; C20, arachidic acid.
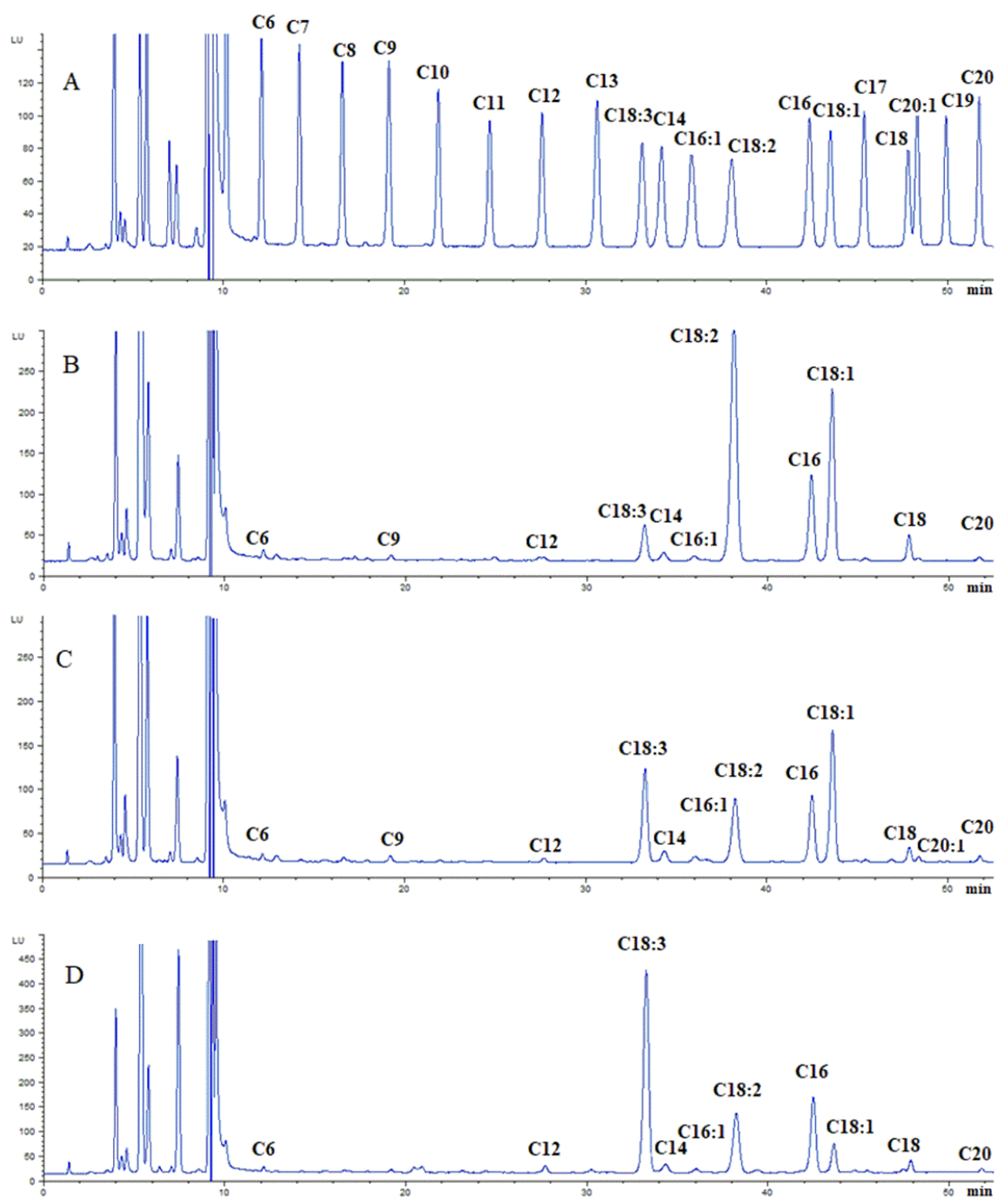

Figure 3. Representative chromatograms for standards (A), fatty acid derivatives in seeds of Nitraria tangutorum Bobr. (B), fatty acid derivatives in peel and pulp of Nitraria tangutorum Bobr. (C) and fatty acid derivatives in leaves of Nitraria tangutorum Bobr. (D). 
Table 2. The measured contents of fatty acids in peel and pulp of Nitraria tangutorum Bobr. ( $\mu \mathrm{g} / \mathrm{g})$.

\begin{tabular}{cccccccc}
\hline \multirow{2}{*}{ Fatty Acid } & \multicolumn{7}{c}{ Region } \\
\cline { 2 - 7 } & Dagele & Zongjia & Nuomuhong & Delingha & Hedong & Dulan & Gahai \\
\hline C6 & $1.01 \pm 0.03$ & $1.15 \pm 0.04$ & $0.98 \pm 0.03$ & $0.87 \pm 0.02$ & $1.11 \pm 0.04$ & $0.94 \pm 0.03$ & $1.22 \pm 0.05$ \\
C7 & nd & nd & nd & nd & nd & nd & nd \\
C8 & nd & nd & nd & nd & nd & nd & nd \\
C9 & $2.41 \pm 0.08$ & $3.07 \pm 0.12$ & $3.11 \pm 0.11$ & $2.09 \pm 0.08$ & $1.97 \pm 0.07$ & $2.06 \pm 0.08$ & $3.21 \pm 1.21$ \\
C10 & nd & nd & nd & nd & nd & nd & nd \\
C11 & nd & nd & nd & nd & nd & nd & nd \\
C12 & $1.19 \pm 0.05$ & $1.43 \pm 0.06$ & $1.25 \pm 0.05$ & $1.07 \pm 0.04$ & $1.32 \pm 0.04$ & $1.65 \pm 0.06$ & $1.47 \pm 0.05$ \\
C13 & nd & nd & nd & nd & nd & nd & nd \\
C18:3 & $123.43 \pm 4.94$ & $90.21 \pm 3.58$ & $145.23 \pm 5.81$ & $89.21 \pm 3.23$ & $96.05 \pm 3.62$ & $112.11 \pm 4.48$ & $137.10 \pm 5.41$ \\
C14 & $10.33 \pm 0.43$ & $12.02 \pm 0.51$ & $10.38 \pm 0.40$ & $10.40 \pm 0.38$ & $10.29 \pm 0.42$ & $15.41 \pm 0.62$ & $12.53 \pm 0.53$ \\
C16:1 & $3.51 \pm 0.15$ & $13.98 \pm 0.52$ & $7.42 \pm 0.27$ & $3.68 \pm 0.14$ & $2.28 \pm 0.06$ & $3.06 \pm 0.13$ & $6.68 \pm 0.18$ \\
C18:2 & $125.16 \pm 5.00$ & $155.62 \pm 6.22$ & $92.33 \pm 3.63$ & $84.47 \pm 2.52$ & $75.71 \pm 3.02$ & $177.61 \pm 6.88$ & $72.43 \pm 2.44$ \\
C16 & $53.75 \pm 2.15$ & $57.65 \pm 1.98$ & $52.14 \pm 2.02$ & $45.04 \pm 1.87$ & $49.45 \pm 2.00$ & $59.38 \pm 2.56$ & $55.16 \pm 2.46$ \\
C18:1 & $179.19 \pm 7.12$ & $139.98 \pm 5.54$ & $145.32 \pm 5.60$ & $181.82 \pm 7.18$ & $116.33 \pm 4.65$ & $135.45 \pm 4.89$ & $183.04 \pm 6.78$ \\
C17 & nd & nd & nd & nd & nd & nd & nd \\
C18 & $36.90 \pm 1.34$ & $39.43 \pm 1.46$ & $42.28 \pm 1.50$ & $42.04 \pm 1.88$ & $23.01 \pm 0.94$ & $56.51 \pm 2.14$ & $41.06 \pm 1.78$ \\
C20:1 & $10.39 \pm 0.42$ & $13.21 \pm 0.48$ & $11.45 \pm 0.44$ & $9.54 \pm 0.38$ & $11.02 \pm 0.44$ & $12.31 \pm 0.45$ & $9.98 \pm 0.36$ \\
C19 & nd & nd & nd & nd & nd & nd & nd \\
C20 & $37.64 \pm 1.45$ & $50.22 \pm 2.08$ & $40.56 \pm 1.64$ & $41.41 \pm 1.59$ & $46.63 \pm 1.82$ & $63.48 \pm 2.43$ & $46.95 \pm 2.25$ \\
Total & & & & & & & \\
Unsaturated & 441.68 & 413 & 401.75 & 368.72 & 301.39 & 440.54 & 409.23 \\
Fatty Acids & & & & & & & \\
Total Fatty & 646.77 & 651.17 & 634.45 & 592.19 & 523.56 & 716.08 & 627.56 \\
Acids & & & & & & & \\
Percentage of & $68.30 \%$ & $63.42 \%$ & $63.32 \%$ & $62.26 \%$ & $57.57 \%$ & $61.52 \%$ & $65.21 \%$ \\
Unsaturated & & & & & & & \\
Fatty Acids & & & & & & \\
\hline & & & & & & \\
& & & & & & & \\
\end{tabular}

Table 3. The measured contents of fatty acids in seeds of Nitraria tangutorum Bobr. $(\mu \mathrm{g} / \mathrm{g})$.

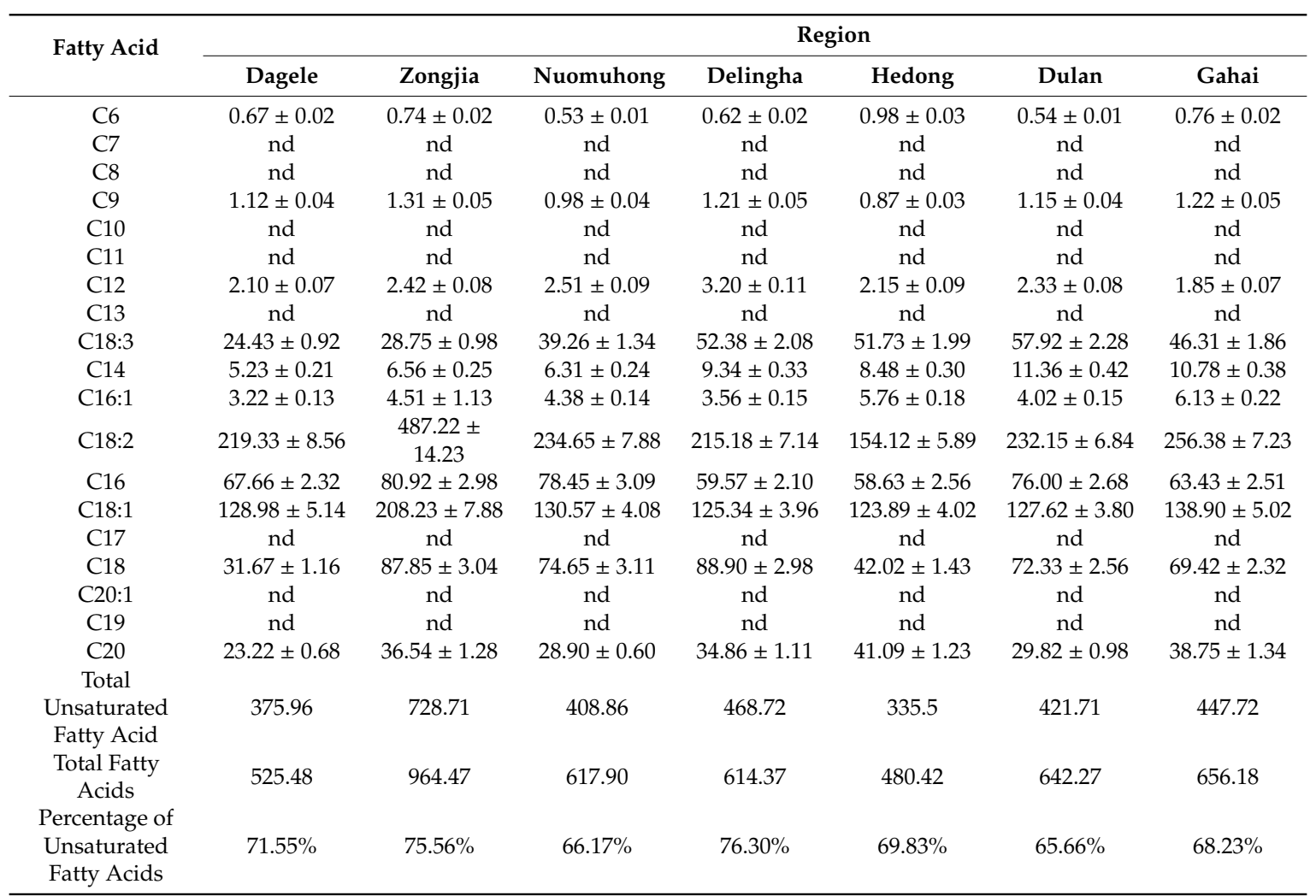


Table 4. The measured contents of fatty acids in leaves of Nitraria tangutorum Bobr. $(\mu \mathrm{g} / \mathrm{g})$.

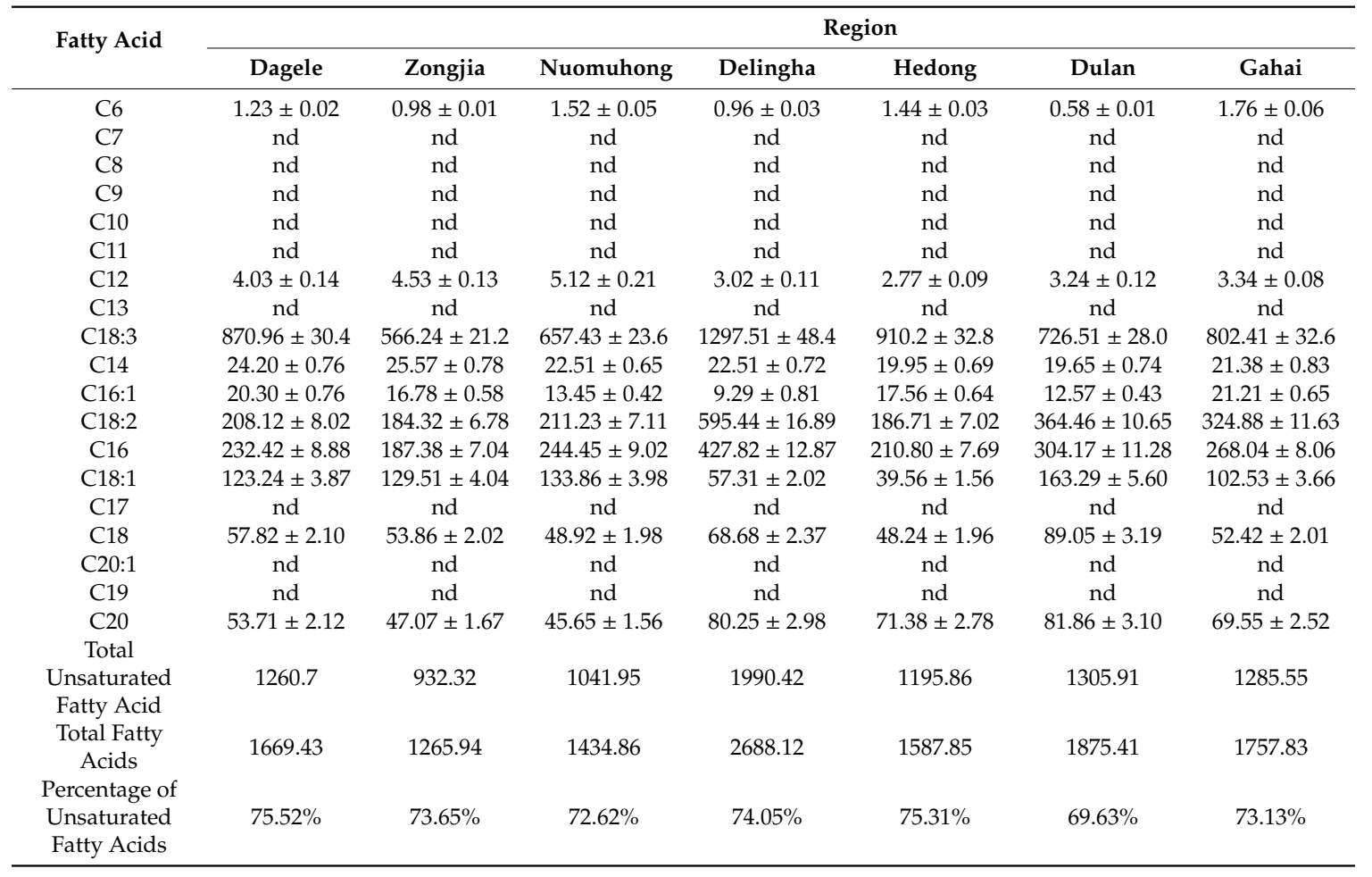

\section{Materials and Methods}

\subsection{Instruments}

The HPLC analysis system was in an Agilent 1260 series HPLC (Agilent Technologies Co. Ltd., Palo Alto, CA, USA) equipped with a quaternary pump (model G1311C), an online-degasser (model G1322B), a thermostated column compartment (model G1316B), an autosampler (model G1329B) and an FLD detector (model G1321B). MSD Trap SL (model G2445D) from Bruker Daltonik (Bremen, Leipzig, Germany) was equipped with an atmospheric pressure chemical ionization (APCI) source (in positive ion model).

\subsection{Reagents and Chemicals}

All FA standards were purchased from Millipore Sigma (St Louis, MO, USA). HPLC grade acetonitrile and methanol were obtained from Yuwang Company, China. Dimethylformamide (DMF), dimethylsulfoxide (DMSO), tetrahydrofuran (THF), sodium carbonate $\left(\mathrm{Na}_{2} \mathrm{CO}_{3}\right)$, potassium oxalate $\left(\mathrm{C}_{2} \mathrm{H}_{2} \mathrm{~K}_{2} \mathrm{O}_{5}\right)$, potassium carbonate $\left(\mathrm{K}_{2} \mathrm{CO}_{3}\right)$ and sodium acetate $\left(\mathrm{CH}_{3} \mathrm{COONa}\right)$ of analytical grade were obtained from Shanghai Chemical Reagent Co. (Shanghai, China). All other reagents used were also of analytical grade unless otherwise stated. Pure water was from Wahaha Group Co., Ltd. (Hangzhou, China). The derivatization reagent NMP was synthesized in our laboratory [30].

\subsection{Plant Material}

Mature fruits and leaves of NTB in seven origins were collected from Qaidam Basin in October 2018 and were identified by senior engineer Changfan Zhou. The detailed sample information was listed in Table 5. The collected samples were dried naturally. Then, the seeds of fruits were separated from the peel and pulp. All dried sample were smashed and sieved through a 60 mesh sieve prior to analysis. 
Table 5. Information of the collected Nitraria tangutorum Bobr. sample in the Qaidam Basin.

\begin{tabular}{cccc}
\hline Origin & Elevation $(\mathbf{m})$ & Longitude & Latitude \\
\hline Dagele & 2679 & $95^{\circ} 45.202^{\prime}$ & $36^{\circ} 27.216^{\prime}$ \\
Zongjia & 2778 & $96^{\circ} 56.850^{\prime}$ & $36^{\circ} 15.959^{\prime}$ \\
Nuomuhong & 2703 & $96^{\circ} 28.233^{\prime}$ & $36^{\circ} 32.338^{\prime}$ \\
Keluke Lake & 2816 & $96^{\circ} 54.180^{\prime}$ & $37^{\circ} 19.024^{\prime}$ \\
Hedong Farm & 2783 & $96^{\circ} 07.799^{\prime}$ & $36^{\circ} 25.657^{\prime}$ \\
Dulan & 3198 & $97^{\circ} 59.375^{\prime}$ & $36^{\circ} 01.921^{\prime}$ \\
Gahai & 2854 & $97^{\circ} 35.766^{\prime}$ & $37^{\circ} 07.535^{\prime}$ \\
\hline
\end{tabular}

\subsection{Preparation of Solutions}

NMP solution $\left(5.4 \times 10^{-3} \mathrm{~mol} / \mathrm{L}\right)$ was prepared by dissolving $20.47 \mathrm{mg}$ NMP in $10 \mathrm{~mL}$ acetonitrile. Nineteen types of FA standard solution $\left(2 \times 10^{-4} \mathrm{~mol} / \mathrm{L}\right)$ was obtained by diluting the corresponding stock solution $\left(1 \times 10^{-2} \mathrm{~mol} / \mathrm{L}\right)$. All solutions were stored at $4{ }^{\circ} \mathrm{C}$ before HPLC analysis.

\subsection{Preparation of Samples}

$200 \mathrm{mg}$ tissue of Nitraria tangutourum Bobr (peel and pulp, seeds or leaves) was weighed into a $10 \mathrm{~mL}$ glass tube. $6 \mathrm{~mL}$ petroleum ether was added into the tube for ultrasonic extraction for $1 \mathrm{~h}$. Then, the sample was centrifuged at $5000 \mathrm{r} / \mathrm{min}$ for $5 \mathrm{~min}$ and the supernatant was collected. After that, another $3 \mathrm{~mL}$ petroleum ether was added into the tube for second round of extraction. Supernatants of two extractions were combined and dried under a gentle nitrogen stream. Finally, the dried substance was dissolved in acetonitrile and exposed to HPLC analysis.

\subsection{Derivatization Procedure}

$20 \mu \mathrm{L}$ of mixed FA standard, $25 \mathrm{mg} \mathrm{K} \mathrm{CO}_{3}, 100 \mu \mathrm{l} \mathrm{DMF}$ and $200 \mu \mathrm{L}$ NMP were added into a $2 \mathrm{~mL}$ vial. The vial was sealed and placed in $90{ }^{\circ} \mathrm{C}$ water bath for $30 \mathrm{~min}$ to make the derivatization complete. Then, the vial was taken out and cooled to room temperature. $250 \mu \mathrm{L}$ of acetonitrile was added to dilute the reaction solution. The diluted solution was filtered through a $0.22 \mu \mathrm{m}$ nylon filter and loaded directly to HPLC apparatus. The injected volume was set to $10 \mu \mathrm{L}$. The derivatization scheme of NMP with FAs is shown in Figure 4.

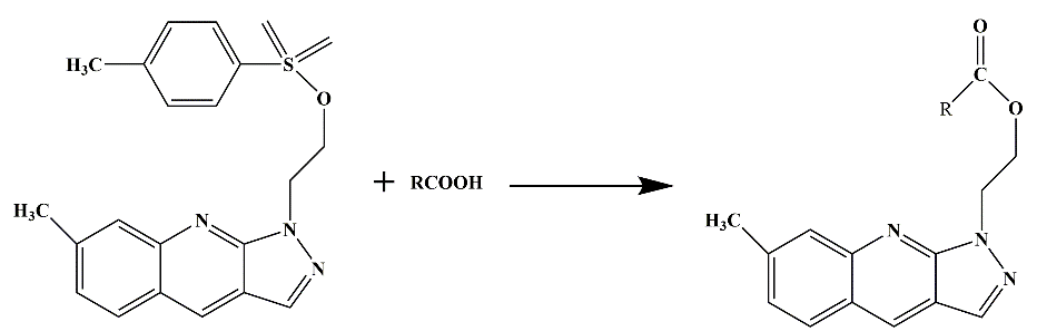

Figure 4. Derivatization reaction process of the derivatized reagent NMP and fatty acid.

\subsection{HPLC Separation and MS Condition}

The mobile phases were A ( $100 \%$ acetonitrile) and B ( $5 \%$ acetonitrile and $95 \%$ water). The gradient condition was set as follows: $0-10 \mathrm{~min}, 40 \%-55 \% \mathrm{~A} ; 10-25 \mathrm{~min}, 40 \%-75 \% \mathrm{~A} ; 25-36 \mathrm{~min}, 70 \%-73 \% \mathrm{~A}$; $36-42 \mathrm{~min}, 73 \%-83 \% \mathrm{~A} ; 42-52 \mathrm{~min}, 83 \%-100 \% \mathrm{~A}$. The temperature and flow rate of mobile phase were set to $35^{\circ} \mathrm{C}$ and $1 \mathrm{~mL} / \mathrm{min}$. The column was equilibrated with the initial mobile phase for $8 \mathrm{~min}$ before the following analysis. Excitation and emission wavelength for fluorescence detection were at $245 \mathrm{~nm}$ and $410 \mathrm{~nm}$, respectively. The chromatographic peaks were characterized by the retention time of the standard controls and further identified by online mass spectrometry. The mass spectrometer from Bruker Daltonik (model G2445D, Bremen Leipzig, Gremany) was equipped with atmospheric pressure chemical ionization (APCI) source (model G1947A). Ion source conditions were as follows: APCI in 
positive ion mode, nebulizer pressure $413 \mathrm{kPa}$, dry gas flow $5.0 \mathrm{~L} / \mathrm{min}$, dry gas temperature $350{ }^{\circ} \mathrm{C}$, capillary voltage of $3500 \mathrm{~V}$ and corona current of $4 \mu \mathrm{A}$ (Pos).

\section{Conclusions}

In this study, a method of simultaneous detection of saturated and unsaturated FAs with NMP labeling-based fluorescence detection and online MS analysis has been successfully established. The method was evaluated by LODs, LOQs, precision and accuracy, which showed good correlation and high sensitivity. The method was applied to analysis of FAs in the peel and pulp, seeds and leaves of NTB from different geographical regions. Results indicated that NTB were rich in FAs especially unsaturated FAs, and the types and contents of FAs varied among tissues. Meanwhile, the same tissues of NTB from different areas contain same kinds of FAs, although the content could differ.

Author Contributions: N.H. conceived and designed the experiments; N.H. and J.O. performed the experiments; H.W. and Q.D. revised the manuscript; N.H. and J.O analyzed the data; N.H. wrote the paper.

Funding: The work was supported by the National Natural Science Foundation (No. 31800297, NO. 31870333), Qinghai Provincial Science Foundation (Grant Number: 2019-ZJ-7023, 2017-SF-A8), Youth Innovation Promotion Association, CAS, Qinghai Province High-end Innovative Thousand Talents Program and the Innovation Platform for the Development and Construction of Special Project of Key Laboratory of Tibetan Medicine Research of Qinghai Province (2017-ZJ-Y11).

Conflicts of Interest: The authors declare no conflict of interest.

\section{References}

1. Pan, X.; Shen, G.; Chen, P.A. Preliminary research on taxonomy and systematics of genus Nitraria. Acta Bot. Yun. 1998, 21, 287-295.

2. Liu, Y.X. Desert Flora in China; Science Press: Beijing, China, 1988.

3. Zhao, K.; Song, J.; Feng, G.; Zhao, M.; Liu, J. Species, types, distribution, and economic potential of halophytes in China. Plant Soil 2011, 342, 495-509. [CrossRef]

4. Hu, N.; Zheng, J.; Li, W.; Suo, Y. Isolation, stability, and antioxidant activity of anthocyanins from Lycium ruthenicum Murray and Nitraria tangutorum Bobr of Qinghai-Tibetan plateau. Sep. Sci. Technol. 2014, 49, 2897-2906. [CrossRef]

5. Suo, Y.R. Research and Development of Nitraria tangutorum in Qaidam Basin; Science Press: Beijing, China, 2010.

6. Duan, J.A.; Williams, I.D.; Che, C.T.; Zhou, R.H.; Zhao, S.X. Tangutorine: A novel $\beta$-carboline alkaloid from Nitraria tangutorum. Tetrahedron Lett. 1999, 40, 2593-2596. [CrossRef]

7. Liu, B.P.L.; Chong, E.Y.Y.; Cheung, F.W.K.; Duan, J.A.; Che, C.T.; Liu, W.K. Tangutorine induces p21 expression and abnormal mitosis in human colon cancer HT-29 cells. Biochem. Pharmacol. 2005, 70, 287-299. [CrossRef]

8. Yang, X.; Zhang, H.; Tang, X.; Liu, Z.; Yang, S.; Ni, J. Nitraria resources in China and their utilization. World For. Res. 2013, 26, 64-68.

9. Wang, H.; Suo, Y.; Wang, X.; Li, Y.; You, J.; Zhao, X. Extraction of Nitraria tangutorum seed oil by supercritical carbon dioxide and determination of free fatty acids by HPLC/APCI/MS with fluorescence detection. Sep. Purif. Technol. 2007, 56, 371-377. [CrossRef]

10. Tan, C.H.; Ghazali, H.M.; Kuntom, A.; Tan, C.P.; Ariffin, A.A. Extraction and physicochemical properties of low free fatty acid crude palm oil. Food Chem. 2009, 113, 645-650. [CrossRef]

11. Kanya, T.S.; Rao, L.J.; Sastry, M.S. Characterization of wax esters, free fatty alcohols and free fatty acids of crude wax from sunflower seed oil refineries. Food Chem. 2007, 101, 1552-1557. [CrossRef]

12. Colussi, G.; Catena, C.; Novello, M.; Bertin, N.; Sechi, L.A. Impact of omega-3 polyunsaturated fatty acids on vascular function and blood pressure: Relevance for cardiovascular outcomes. Nutr. Metab. Cardiovas. 2017, 27, 191-200. [CrossRef]

13. Currie, E.; Schulze, A.; Zechner, R.; Walther, T.C.; Farese Jr, R.V. Cellular fatty acid metabolism and cancer. Cell Metab. 2013, 18, 153-161. [CrossRef] [PubMed] 
14. Remely, M.; Aumueller, E.; Merold, C.; Dworzak, S.; Hippe, B.; Zanner, J.; Pointner, A.; Brath, H.; Haslberger, A.G. Effects of short chain fatty acid producing bacteria on epigenetic regulation of FFAR3 in type 2 diabetes and obesity. Gene 2014, 537, 85-92. [CrossRef] [PubMed]

15. Freigang, S.; Ampenberger, F.; Weiss, A.; Kanneganti, T.D.; Iwakura, Y.; Hersberger, M.; Kopf, M. Fatty acid-induced mitochondrial uncoupling elicits inflammasome-independent IL-1 [alpha] and sterile vascular inflammation in atherosclerosis. Nat. Immunol. 2013, 14, 1045-1053. [CrossRef] [PubMed]

16. Park, Y.; Lee, A.; Shim, S.C.; Lee, J.H.; Choe, J.Y.; Ahn, H.; Choi, C.B.; Sung, Y.K.; Bae, S.C. Effect of n-3 polyunsaturated fatty acid supplementation in patients with rheumatoid arthritis: A 16-week randomized, double-blind, placebo-controlled, parallel-design multicenter study in Korea. J. Nutr. Biochem. 2013, 24, 1367-1372. [CrossRef] [PubMed]

17. Nestel, P.; Clifton, P.; Colquhoun, D.; Noakes, M.; Mori, T.A.; Sullivan, D.; Thomas, B. Indications for omega-3 long chain polyunsaturated fatty acid in the prevention and treatment of cardiovascular disease. Heart Lung Circ. 2015, 24, 769-779. [CrossRef] [PubMed]

18. Tan, J.; McKenzie, C.; Potamitis, M.; Thorburn, A.N.; Mackay, C.R.; Macia, L. The role of short-chain fatty acids in health and disease. Adv. Immunol. 2014, 121, 119.

19. Pusvaskiene, E.; Januskevic, B.; Prichodko, A.; Vickackaite, V. Simultaneous Derivatization and dispersive liquid-liquid microextraction for fatty acid GC determination in water. Chromatographia 2009, 69, 271-276. [CrossRef]

20. Kim, N.S.; Lee, J.H.; Han, K.M.; Kim, J.W.; Cho, S.; Kim, J. Discrimination of commercial cheeses from fatty acid profiles and phytosterol contents obtained by GC and PCA. Food Chem. 2014, 143, 40-47. [CrossRef]

21. Gamazo-Vázquez, J.; Garcia-Falcón, M.S.; Simal-Gándara, J. Control of contamination of olive oil by sunflower seed oil in bottling plants by GC-MS of fatty acid methyl esters. Food Control 2003, 14, 463-467. [CrossRef]

22. Zelinkova, Z.; Giri, A.; Wenzl, T. Assessment of critical steps of a GC/MS based indirect analytical method for the determination of fatty acid esters of monochloropropanediols (MCPDEs) and of glycidol (GEs). Food Control 2017, 77, 65-75. [CrossRef]

23. Amorello, D.; Orecchio, S.; Pace, A.; Barreca, S. Discrimination of almonds (Prunus dulcis) geographical origin by minerals and fatty acids profiling. Nat. Prod. Res. 2016, 30, 2107-2110. [CrossRef] [PubMed]

24. Bauza, T.; Blaise, A.; Daumas, F.; Cabanis, J.C. Determination of biogenic amines and their precursor amino acids in wines of the Vallée du Rhône by high-performance liquid chromatography with precolumn derivatization and fluorimetric detection. J. Chromatogr. A 1995, 707, 373-379. [CrossRef]

25. Brondz, I. Development of fatty acid analysis by high-performance liquid chromatography, gas chromatography, and related techniques. Anal. Chim. Acta 2002, 465, 1-37. [CrossRef]

26. Grob, K.; Biedermann, M. The two options for sample evaporation in hot GC injectors: Thermospray and band formation. Optimization of conditions and injector design. Anal. Chem. 2002, 74, 10-16. [CrossRef] [PubMed]

27. Gutnikov, G. Fatty acid profiles of lipid samples. J. Chromatogr B Biomed. Sci. Appl. 1995, 671, 71-89. [CrossRef]

28. Püttmann, M.; Krug, H.; von Ochsenstein, E.; Kattermann, R. Fast HPLC determination of serum free fatty acids in the picomole range. Clin. Chem. 1993, 39, 825-832.

29. Shukla, V.K. Recent advances in the high performance liquid chromatography of lipids. Prog. Lipid. Res. 1988, 27, 5-38. [CrossRef]

30. Wang, A.; Li, G.; You, J.; Ji, Z. A new fluorescent derivatization reagent and its application to free fatty acid analysis in pomegranate samples using HPLC with fluorescence detection. J. Sep. Sci. 2013, 36, 3853-3859. [CrossRef]

31. Zhang, S.; You, J.; Zhou, G.; Li, C.; Suo, Y. Analysis of free fatty acids in Notopterygium forbesii Boiss by a novel HPLC method with fluorescence detection. Talanta 2012, 98, 95-100. [CrossRef]

32. You, J.; Zhao, X.; Suo, Y.; Li, Y.; Wang, H.; Chen, G. Determination of long-chain fatty acids in bryophyte plants extracts by HPLC with fluorescence detection and identification with MS. J. Chromatogr. B 2007, 848, 283-291. [CrossRef] 
33. Wang, Y.; Luan, G.; Zhou, W.; You, J.; Hu, N.; Suo, Y. 2-(4-Amino)-Phenyl-1-Hydrogen-Phenanthrene [9-d] Imidazole as a Novel Fluorescent Labeling Reagent for Determination of Fatty Acids in Raspberry. Food Anal. Method 2018, 11,1-15. [CrossRef]

34. Zeng, Z.; Ji, Z.; Hu, N.; Bai, B.; Wang, H.; Suo, Y. A sensitive pre-column derivatization method for the analysis of free fatty acids by RP-HPLC with fluorescence detector and its application to Caragana species. J. Chromatogr. B 2017, 1064, 151-159. [CrossRef] [PubMed]

Sample Availability: Samples of the Nitraria tangutorum Bobr. are available from the authors.

(C) 2019 by the authors. Licensee MDPI, Basel, Switzerland. This article is an open access article distributed under the terms and conditions of the Creative Commons Attribution (CC BY) license (http://creativecommons.org/licenses/by/4.0/). 